\title{
Preparing Astronomical Videotapes
}

Françoise Suagher $^{1}$, Pierre Chopard ${ }^{1}$, Pierre Magnien ${ }^{1}$, Jean-Pierre Marchand ${ }^{1}$, and Jean Paul Parisot ${ }^{2}$

1 Association Astronomique de Franche Comté, 34 av. de l'Observatoire, F-25000 Besançon, France

${ }^{2}$ Observatoire de Besançon, 41 bis av. de l'Observatoire, F-25044 Besançon Cedex, France

In 1982, the Association Astronomique de Franche Comté prepared a slide show entitled "Meet History's Comet". This had been so successful, being presented in more than 100 towns, that a second show entitled "Worlds in the Sky" about the Solar System had been prepared and made by an audio-visual workshop. The high cost $(20000 \mathrm{Fr})$ had been largely covered by a grant.

\section{Transmission of Astronomical Data and Information by the A.F.A. Videotext System}

Bernard Pellequer

Observatoire Astronomique, B.P. 14, F-34150 Aniane, France

Following the introduction of a videotext system in France using MINITEL terminals, the Association Française d'Astronomie organized an astronomical information service. This covers celestial and space events, location of the planets, lists of societies and clubs, bibliography, etc. A practical demonstration of the system in use was given.

\section{The Solar System Promenade}

\section{Andreas Tarnutzer}

Schweitzerische Astronomische Gesellschaft, Hirtenhofstrasse 9, CH-6005 Luzern, Switzerland

In order to convey the dimensions and relative scale of the Solar System all sizes and distances are reduced by a factor of $10^{9}$, resulting in a solar diameter of $1.4 \mathrm{~m}$, a diameter of $5 \mathrm{~mm}$ for Mercury, and a mean Sun-Pluto distance of close to $6 \mathrm{~km}$. Stainless steel models of the planets (and the Moon) are mounted at appropriate distances from a yellow steel sphere representing the Sun. Ten of these Solar System Promenades have been constructed in Switzerland. 